\title{
Effect of Rhizobium on Growth and Biomass Production of Rice
}

\author{
ARM Solaiman ${ }^{1 *}$, GMA Hossain $^{1}$ and MAB Mia ${ }^{2}$ \\ ${ }^{I}$ Department of Soil Science, Bangabandhu Sheikh Mujibur Rahman Agricultural University, Gazipur-1706, Bangladesh, ${ }^{2}$ Department of Crop \\ Botany, Bangabandhu Sheikh Mujibur Rahman Agricultural University, Gazipur-1706, Bangladesh
}

(Received 20 August 2011; Accepted 03 December 2011)

\begin{abstract}
To characterize twenty Rhizobium strains isolated from nodules of lentil, grasspea and chickpea, an experiment was conducted in the Soil Microbiology laboratory of the Bangabandhu Sheikh Mujibur Rahman Agricultural University, Gazipur, Bangladesh. The isolates were tested for growth on Congo red Yeast Extract Mannitol (YEM) agar, peptone glucose agar, and YEM agar containing Bromothymol blue (BTB). All the strains except Ls 12 absorbed Congo red dye very weekly. Except Le 2 strains, isolated from lentil showed no growth in peptone glucose agar. All the strains isolated from grasspea and chickpea showed moderate growth on this medium. All the strains were fast-growing and showed acidic reaction on YEM agar medium. Among the strains isolated from lentil, Le 1, Le 2 and Le 4 produced moderate turbidity while Le 3, Le 6, Le 7 and Le 8 produced high turbidity in YEM broth. All the strains isolated from grasspea except Ls 3 and chickpea except Ca 1 produced moderate turbidity in YEM broth medium. Strains Ls 3 and Ca 1 produced high turbidity. To assess the effect of ten of these Rhizobium isolates viz. Le 1, Le 4, Le 6, Le 8, Ls 1, Ls 2, Ls 6, Ls 7, Ca 3 and Ca 4 on growth and biomass production of rice, a follow-up experiment was conducted in the same laboratory. Root length of rice was significantly increased over control (without inoculation) due to inoculation with different Rhizobium strains. The highest root length $(9.63 \mathrm{~cm})$ was obtained by inoculation with strain Ls 6 isolated from lentil. All the Rhizobium strains produced significantly higher shoot length, fresh and dry biomass over control. The highest shoot length $(16.50 \mathrm{~cm})$, fresh biomass $(138.3 \mathrm{mg})$ and dry biomass $(27.75$ mg) were also obtained from the strain Ls 6.
\end{abstract}

Key words: Isolation, Characterization, Rhizobium, Rice

\section{Introduction}

Rice is unquestionably the main cereal food for the people of Bangladesh. It occupies $74.77 \%$ of the total cropped area ${ }^{1}$, supplies $92 \%$ of cereal food. To maintain self-sufficiency in rice, Bangladesh will have to continue to expand rice production by raising yields at a rate that is at least equal to population growth until the demand for rice has stabilized. Meeting the challenge of increasing rice production will become increasingly difficult in Bangladesh as rice areas is continuously shrinking to meet the growing demand for high-value crops and for urban and industrial development. Therefore, it is necessary to increase the production capacity per unit area which would require high inputs. Another alternative to increase crop production is use of beneficial microorganism, which could lead to more productive and sustainable agriculture without harming the environment. Soilplant-microbe interaction has got much importance in recent decades. Many types of microorganisms are known to inhabit in soil, especially rhizosphere and play important role in plant growth and development. The most inoculation studies have focused on free living diazotrophs, although a few reports indicate Rhizobium can act as plant growth promoting rhizobacteria (PGPR) $)^{2}$. The PGPR influence the crop growth and development by releasing plant growth regulators ${ }^{3}$ and improving morphological characteristics of inoculated roots ${ }^{4}$, which favored nutrient uptake ${ }^{5}$. The growth promoting effects of rhizobacteria may include phytohormone production ${ }^{6}, \mathrm{~N}_{2}$ fixation ${ }^{7}$ and more efficient use of nutrients ${ }^{6}$. Feng et al. ${ }^{8}$ reported that inoculation of rhizobia to rice produced significantly higher root and shoot biomass; increased their photosynthetic rate, stomatal conductance, transpiration velocity, water utilization efficiency, and flag leaf area (considered to possess the highest photosynthetic activity); and accumulated higher levels of indole acetic acid and gibberellins growth-regulating phytohormones. No work has so far been conducted in our agro-climatic conditions to observe the effect of Rhizobium as PGPR on rice. Keeping these facts in mind the present study was under taken to characterize Rhizobium strains isolated from root nodules of different leguminous crops, and also to assess their effectiveness on root and shoot development and biomass production of $\mathrm{T}$. Aman rice.

\section{Materials and Methods}

Twenty plant samples with rhizosphere soil were collected from different rice growing areas of Bangladesh to isolate Rhizobium 
strains. Samples were collected from Kushtia (AEZ-11), Rajbari (AEZ-11), Faridpur (AEZ-12) and Patuakhali (AEZ-13) districts of Bangladesh. Root with nodules from different leguminous crop viz. lentil (Lens esculentus), grass pea (Lathyrus sativus) and chickpea (Cicer arietinum) and rhizosphere soils were collected for isolation and characterization of Rhizobium strains. Samples were selected randomly from farmers' field of the respected AEZs. Nodules separated from roots of different leguminous crops were washed in fresh water and preserved in vials containing silica gel. The collected nodules were surface sterilized. The nodules were then crushed and streaked on Yeast Extract Mannitol (YEM) agar medium contained in petridises with the help of sterile loop. Single colonies of the isolates formed on the medium were preserved for further studies.

A preliminary experiment was conducted in the Soil Microbiology laboratory of the Bangabandhu Sheikh Mujibur Rahman Agricultural University to characterize Rhizobium strains isolated from nodules of those crops. The strains were assessed for colony characteristics, growth rate and acid/alkali production in laboratory media with a view to know their basic properties prior to more intensive study on their performance in respect of growth and biomass production of rice. YEM containing the following constituents: $\mathrm{K}_{2} \mathrm{HPO}_{4}(0.5 \mathrm{~g}), \mathrm{MgSO}_{4} .7 \mathrm{H}_{2} \mathrm{O}(0.2 \mathrm{~g}), \mathrm{NaCl}(0.1 \mathrm{~g})$, $\mathrm{CaCO}_{3}(3.0 \mathrm{~g}), \mathrm{FeCl}_{3} \cdot 6 \mathrm{H}_{2} \mathrm{O}(0.01 \mathrm{~g})$, Mannitol $(10 \mathrm{~g})$, yeast extract $(0.5 \mathrm{~g})$, agar (Difco) $(10 \mathrm{~g})$, Congo red $(02.5 \%$ solution $)(10 \mathrm{ml})$, deionized water to 1 litre was used. The initial $\mathrm{pH}$ of the medium was 7.3 which was adjusted to 7.0 by adding $0.1 \mathrm{~N} \mathrm{HCl}$ solution. The medium was inoculated with the Rhizobium strains and incubated for one week. Colonies on plates were observed for their morphology and appearance. The YEM agar medium containing bromothymol blue indicator was used for identification of strains. The reaction of the rhizobial strains on this medium was noted every week up to four weeks. Fast-growing rhizobial strains produce acid in this medium, turning the medium yellow and slow growing rhizobia produce alkali which turns the medium blue ${ }^{9}$.

An in vitro experiment was conducted in the same laboratory to study the effect of Rhizobium isolates on growth and biomass production of rice. Ten of twenty isolates collected from different leguminous crops were used for the experiment. Among them four isolates viz. Le 1, Le 4, Le 6 and Le 8 were taken from lentil, four isolates viz. Ls 1, Ls 2, Ls 6 and Ls 7 were taken from grasspea and two isolates viz. Ca 3 and $\mathrm{Ca} 4$ were taken from chickpea. Those isolates of rhizobia were grown in YEM broth until turbid. Rice variety BSMRAU Dhan 1 was used as the test crop. The composition of rooting solution used in this experiment was ( $\mathrm{gL}^{-}$ 1): $\mathrm{KNO}_{3}(0.505), \mathrm{Ca}\left(\mathrm{NO}_{3}\right)_{2} \cdot 4 \mathrm{H}_{2} \mathrm{O}(0.335), \mathrm{Mg} \mathrm{SO}_{4} \cdot 7 \mathrm{H}_{2} \mathrm{O}(0.37)$, $\mathrm{NaNO}_{3}(0.17), \mathrm{KCl}\left(1.05 \times 10^{-3}\right), \mathrm{KH}_{2} \mathrm{PO}_{4}(0.136), \mathrm{Fe}-\mathrm{EDTA}\left(3.55 \times 10^{-}\right.$ $\left.{ }^{3}\right), \mathrm{MnSO}_{4} \cdot 4 \mathrm{H}_{2} \mathrm{O}\left(0.81 \times 10^{-3}\right), \mathrm{H}_{3} \mathrm{BO}_{3}\left(0.57 \times 10^{-3}\right), \mathrm{ZnSO}_{4} \cdot 7 \mathrm{H}_{2} \mathrm{O}$ $\left(0.22 \times 10^{-3}\right), \mathrm{CuSO}_{4} .5 \mathrm{H}_{2} \mathrm{O}\left(0.04 \times 10^{-3}\right),\left(\mathrm{NH}_{4}\right) 6 \mathrm{Mo}_{7} \mathrm{O}_{24} \cdot 4 \mathrm{H}_{2} \mathrm{O}$ $\left(0.02 \times 10^{-3}\right)$ and distilled water- $1000 \mathrm{ml}$. Stock solution of KNO3, $\mathrm{Ca}\left(\mathrm{NO}_{3}\right)_{2} \cdot 4 \mathrm{H}_{2} \mathrm{O}, \mathrm{KH}_{2} \mathrm{PO} 4, \mathrm{Fe}-\mathrm{EDTA}$ and all other micro nutrients
$\left(\mathrm{MnSO}_{4} \cdot 4 \mathrm{H}_{2} \mathrm{O}, \mathrm{H}_{3} \mathrm{BO}_{3}, \mathrm{ZnSO}_{4} .7 \mathrm{H}_{2} \mathrm{O}, \mathrm{CuSO}_{4} .5 \mathrm{H}_{2} \mathrm{O}\right.$, $\left.\left(\mathrm{NH}_{4}\right) 6 \mathrm{Mo}_{7} \mathrm{O}_{24} \cdot 4 \mathrm{H}_{2} \mathrm{O}\right)$ were prepared separately ${ }^{10}$. The $\mathrm{pH}$ of the solution was adjusted to 6.8 . Fifty five millilitre of seedling media was taken in each boiling tubes $(200 \mathrm{~mm} \times 20 \mathrm{~mm})$. Blotting paper (50 mm long) rolls were placed at the top of the tubes and the mouth of the tubes was closed with cotton. These boiling tubes containing seedling media were autoclaved for 15 minutes at $121^{\circ} \mathrm{C}$ before use. The blotting paper rolls were then slid down towards the rooting solution until the top of the solution reached just below the top of the blotting paper leaving the bottom of the tubes free from blotting paper. Roots of surface sterilized, germinated seedlings ( 3 days old) were soaked for 30 minutes in $1 \mathrm{ml}$ inoculant of specific bacteria and it was distributed among four respective test tubes $(0.25 \mathrm{ml}$ each of 4 test tubes $)$. After that $1 \mathrm{ml}$ of specific bacterial inoculant was added to each test tube. Inoculation of rhizobial strains were done with approximately $10^{8}$ cells $\mathrm{ml}^{-1}$. With the aid of the flamed and cooled end of a forceps the surface sterilized germinated rice seedlings were transferred to each tube into a slit made on the top of the seedling media. These test-tubes were placed on packing foam by making holes on it and were covered by black paper roles from the surface of the packing foam to the top of the filter paper to exclude horizontal light from the roots. The experiment was conducted in CRD design with four replications. The rice seedlings were allowed to grow for four weeks. Data on root and shoot length, fresh and dry biomass were taken.

Data on various characters of the crop were statistically analyzed to find out the significance of variation resulting from the experimental treatments. For this purpose, analysis of variance was worked out for each character of the crop. The difference between treatment means was compared by Duncan's Multiple Range Test.

\section{Results and Discussion}

Isolation and characterization of Rhizobium strains from different leguminous crops

\section{Growth on Congo red YEM agar}

In general, colonies of rhizobial strains absorbed very little of the Congo red dye. Results presented in Tables 1-3 show that all the strains isolated from lentil (Le 1, Le 2, Le 3, Le 4, Le 6, Le 7 and Le 8), chickpea (Ca 1, Ca 2, Ca 3, Ca 4 and Ca 5) and grasspea (Ls 1, Ls 2, Ls 3, Ls 4 Ls 6, Ls 7 and Ls 8) except Ls 12 absorbed the dye very weekly whereas moderate absorption was done in case of Ls 12. This result corroborates with the findings of Trinick ${ }^{11}$ and Talukder et al. ${ }^{12}$ who reported that rhizobia absorbed the dye weakly compared with other bacteria.

\section{Growth on peptone glucose agar}

Growth in peptone glucose agar as reported by Vincent ${ }^{13}$ indicates that most of the Rhizobium strains grow either poorly or moderately in this medium. In the present study, all the strains except Le 2 isolated from lentil showed no growth whereas Le 2 showed poor growth in this medium. All the strains isolated from grasspea and chickpea showed poor growth in this medium (Tables 1-3). 


\section{Colony characteristics on YEM agar}

Rhizobium strains are classified as fast and slow growing depending on growth on YEM agar. All the strains isolated from lentil, grasspea and chickpea showed fast growth in YEM agar (Tables 1-3). Strains Le 1, Le 6, Le 7, Le 8 and Ls 4 produced bigger colonies and more gum than the rest of the strains on YEM agar medium. Colonies of all the strains except Le 1, Le 6, Le 7, Le 8 and Ls 4 appeared small and separate with slight gum production. The texture of the gum was sticky. This result resembles with that of Talukder et al. ${ }^{12}$.

\section{Acid/alkali production in YEM agar medium containing} bromothymol blue indicator

The importance of production of acid or alkali by the various rhizobia as reported by Norris ${ }^{14}$ has been emphasized when considering Rhizobium taxonomy. In this study all the Rhizobium strains isolated from lentil, grasspea and chickpea showed acidic reactions throughout their four weeks of growth (Tables 1-3). These strains turned green colour of the medium to yellow.

\section{Growth on YEM broth}

Results presented in Tables 1-3 indicate that Rhizobium strains showed visible turbidity in YEM broth after 5 to 7 days of incubation. Among the strains isolated from lentil Le 1, Le 2, and Le 4 produced moderate turbidity while Le 3, Le 6, Le 7 and Le 8 produced high turbidity in this medium. All the strains isolated from grasspea except Ls 3 and chickpea except $\mathrm{Ca} 1$ produced moderate turbidity in YEM broth. Strains Ls 3 and $\mathrm{Ca} 1$ produced high turbidity. The differences in texture of extra cellular polysaccharide of the fast- and slow-growing rhizobia have been shown to be due to differences in monosaccharide comparison ${ }^{15}$.

Effect of inoculation of Rhizobium strains on growth and biomass production of rice

Root length

Results presented in Table 4 revealed that root length of rice was significantly increased over control due to inoculation of different Rhizobium strains. The highest root length $(9.63 \mathrm{~cm})$ was

Table 1. Characteristics of some Rhizobium strains isolated from root nodules of lentil

\begin{tabular}{|c|c|c|c|c|c|}
\hline Strains & $\begin{array}{l}\text { Growth on congo red } \\
\text { YEM agar } \\
\text { (absorption of dye) }\end{array}$ & $\begin{array}{l}\text { Growth on peptone } \\
\text { glucose agar }\end{array}$ & $\begin{array}{c}\text { Colony characteristics } \\
\text { on YEM agar } \\
\text { (Fast/ slow) }\end{array}$ & $\begin{array}{l}\text { Acid/ alkali production } \\
\text { in YEM agar medium } \\
\text { containing BTB }\end{array}$ & $\begin{array}{c}\text { Growth in YEM } \\
\text { broth }\end{array}$ \\
\hline Le 2 & Slight & Poor & Fast & Acid & Moderate turbidity \\
\hline Le 3 & Slight & Nil & Fast & Acid & High turbidity \\
\hline Le 4 & Slight & Nil & Fast & Acid & Moderate turbidity \\
\hline Le 8 & Slight & Nil & Fast & Acid & High turbidity \\
\hline
\end{tabular}

Table 2. Characteristics of some Rhizobium strains isolated from root nodules of grasspea

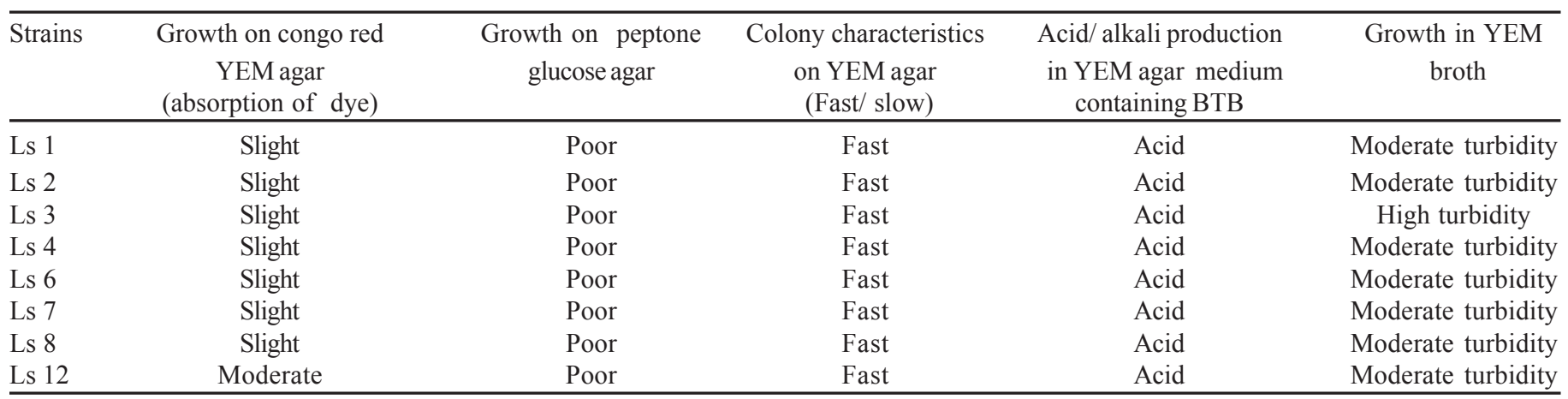

Table 3. Characteristics of some Rhizobium strains isolated from root nodules of chickpea

\begin{tabular}{|c|c|c|c|c|c|}
\hline Strains & $\begin{array}{c}\text { Growth on congo red } \\
\text { YEM agar } \\
\text { (absorption of dye) }\end{array}$ & $\begin{array}{l}\text { Growth on peptone } \\
\text { glucose agar }\end{array}$ & $\begin{array}{c}\text { Colony characteristics } \\
\text { on YEM agar } \\
\text { (Fast/ slow) }\end{array}$ & $\begin{array}{c}\text { Acid/ alkali production } \\
\text { in YEM agar medium } \\
\text { containing BTB }\end{array}$ & $\begin{array}{c}\text { Growth in YEM } \\
\text { broth }\end{array}$ \\
\hline $\mathrm{Ca} 2$ & Slight & Poor & Fast & Acid & Moderate turbidity \\
\hline $\mathrm{Ca} 3$ & Slight & Poor & Fast & Acid & Moderate turbidity \\
\hline $\mathrm{Ca} 4$ & Slight & Poor & Fast & Acid & Moderate turbidity \\
\hline
\end{tabular}


Table 4. Effect of Rhizobium inoculation on growth and biomass production of rice

\begin{tabular}{|c|c|c|c|c|}
\hline Treatment & Root length (cm) & Shoot length $(\mathrm{cm})$ & Fresh biomass yield (mg) & Dry biomass yield (mg) \\
\hline Le 4 & $9.00 \mathrm{ab}$ & $16.38 \mathrm{a}$ & $92.25 \mathrm{bc}$ & $21.00 \mathrm{~b}$ \\
\hline Le 6 & $8.75 \mathrm{ab}$ & $15.25 \mathrm{ab}$ & $93.25 \mathrm{bc}$ & $22.75 \mathrm{ab}$ \\
\hline Le 8 & $7.38 \mathrm{bc}$ & $15.63 \mathrm{a}$ & $100.8 \mathrm{abc}$ & $21.50 \mathrm{ab}$ \\
\hline Ls 2 & $8.13 \mathrm{abc}$ & $16.13 \mathrm{a}$ & $109.50 \mathrm{abc}$ & $21.75 \mathrm{ab}$ \\
\hline Ls 6 & $9.63 \mathrm{a}$ & $16.50 \mathrm{a}$ & $138.30 \mathrm{a}$ & $27.75 \mathrm{a}$ \\
\hline Ls 7 & $9.38 \mathrm{ab}$ & $16.00 \mathrm{a}$ & $78.50 \mathrm{bc}$ & $22.50 \mathrm{ab}$ \\
\hline $\mathrm{Ca} 3$ & $6.25 \mathrm{~cd}$ & $13.75 \mathrm{ab}$ & $107.80 \mathrm{abc}$ & $21.00 \mathrm{~b}$ \\
\hline $\operatorname{LSD}(0.05)$ & 1.746 & 2.882 & 38.17 & 5.782 \\
\hline
\end{tabular}

obtained by strain Ls 6 isolated from lentil while the lowest (5.5 $\mathrm{cm}$ ) was obtained from control (without inoculation). Strains Le 1, Le 4, Le 6, Ls 7, Ca 4, Ls 1 and Ls 2 were statistically identical with Ls 6 regarding root length. This result corroborates with the findings of Afzal et al. ${ }^{16}$ who reported highest root weight due to inoculation of Rhizobium in wheat.

\section{Shoot length}

All the Rhizobium strains produced significantly higher shoot length over control (Table 4). The highest shoot length (16.45 $\mathrm{cm})$ was obtained from Ls 6 while the lowest $(12.13 \mathrm{~cm})$ was from control. This result also supported the findings of Afzal et al. ${ }^{16}$ who found higher plant height with Rizobium inoculation in wheat.

\section{Fresh biomass yield}

Fresh biomass of rice increased significantly over control due to Rhizobium strains inoculation (Table 4). The highest fresh biomass $(138.3 \mathrm{mg}$ ) was obtained from inoculation of Ls 6 while the lowest (69.5 mg) was obtained from control. Strain Le 8, Ls 1, Ls 2 and $\mathrm{Ca} 3$ and $\mathrm{Ca} 4$ were statistically similar with Ls 6 regarding fresh biomass yield (Table 4) which correlated with the findings of Francine et al. ${ }^{17}$ who reported that inoculation of rhizobia to rice produced significantly higher root and shoot biomass.

Dry biomass yield

Dry biomass yield of rice was increased significantly over control due to different Rhizobium strains inoculation (Table 4). The highest dry matter $(27.75 \mathrm{mg})$ was obtained from Ls 6 and the lowest (13.25 mg) was from control (Table 4). Strain Le 6, Le 8, Ls 2 and Ls 7 produced statistically similar dry biomass yield with Ls 6 which was at par with the findings of Solaiman et al. ${ }^{18}$ who reported that Rhizobium inoculants increased dry matter yield in chickpea which also corroborates with the findings of Francine et al. ${ }^{17}$ as well.

\section{Conclusion}

It may be concluded that all the Rhizobium strains isolated from different leguminous crops showed standard reactions in the laboratory media and significantly increased root and shoot growth and biomass production of rice. Among the strains Ls 6 which was isolated from grasspea performed best in all the parameters studied.

\section{References}

1. Annonymous. 2009. Statistical Year Book, 2009. Bangladesh Bureau of Statistics, Dhaka, Bangladesh.

2. Höflich G. 2000. Colonization and growth promotion of non-legumes by Rhizobium bacteria. Microbial Biosystems: New Frontiers. In: Bell, C.R., M. Brylinsky and P. Johnson-Green ( e d s . ), Proceedings of the $8^{\text {th }}$ International Symposium on Microbial Ecology, pp: 827-30. Atlantic Canada Society for Microbial Ecology, Halifax, Canada.

3. Volpin H and Philips DA. 1998. Respiratory elicitors from Rhizobium meliloti effect intact alfalfa roots. Plant Physiol. 116: 777-83.

4. Biswas JC. 1998. Effect of Nitrogen Fixing Bacteria on Growth Promotion of Lowland Rice (Oryza sativa L.). Ph. D Thesis, Department of Soil Science University of Phillipines, Los Banos 24.

5. Okon Y and Kapulnik Y. 1986. Development and function of Azospirillum inoculated roots. Plant Soil. 90: 3-167.

6. Chabot R, Antoun H and Cescas MP. 1996. Growth promotion of maize and lettuce by phosphate-solubilizing Rhizobium leguminosarum biovar phaseoli. Plant Soil. 184: 311-21.

7. Urquiaga S, Cruz KHS and Boddey RM. 1992. Contribution of nitrogen fixation to sugar cane: nitrogen-15 and nitrogen-balance estimates. Soil Sci Soc America Proc. 56: 105-14.

8. Feng C, Shi-Hua S, Cheng HP, Jing YX, Yanni Y and Dazzo FB. 2005. Ascending migration of endophytic rhizobia, from roots to leaves, inside rice plants and assessment of benefits to rice growth physiology. Appl Environ Microbiol. 71(11): 7271-8. 
9. Solaiman ARM and Rabbani MG. 2005. Effect of Rhizobium inoculants, compost and nitrogen on edible-podded pea. Bang $J$ Microbiol. 21(1): 36-41.26.

10. Shamsuddin ZH, Amir HG and Mia MAB. 1998. Azospirrilum as a bioenhancer and biofertilizer for banana and oil palm seedlings. Biotechnology for sustainable utilization of biological resources in the tropics. Vol. 13. pp. 326-338.

11. Trinick MJ. 1982. Biology, in nitrogen fixation volume 2: Rhizobium (WJ Broughton Ed). pp. 76-146. CGRendium press, oxford.

12. Talukder MS, Solaiman ARM, Khanam D and Rabbani MG. 2008. Characterisation of some Rhizobium isolates and their effectiveness on pea. Bang J Microbiol. 25(1): 45-48.

13. Vincent JM. 1970. A manual for the practical study of root nodule bacteria. Blackwell Science Publication. Oxford.
14. Norris DO. 1965. Acid predication of Rhizobium. A unifying concept. Plant Soil. 22. 143-166.

15. Bailey RW, Greenwood RM and Craig A. 1971. Extracellular polysaccharides of Rhizobium strains associated with Lotus species. J Gen Microbiol. 65: 315-324.

16. Afzal A and Asghari B. 2008. Rhizobium and phosphate solubilizing bacteria improve the yield and phosphorus uptake in wheat (Triticum aestivum L). Intl J Agri Biol. 10: 85-88.

17. Francine M, Perrine W, Gartner E, Charles HH, Becker A and Barry GR. 2007. Rhizobium-initiated rice growth inhibition caused by nitric oxide accumulation. Mol Plant Microbe Interaction. 20(3): 283292.

18. Solaiman ARM, Talukdar MS and Rabbani MG. 2010. Influence of some Rhizobium strains on chickpea: nodulation, dry matter yield and nitrogen uptake. Bang J Microbiol. 27 (2): 61-64. 